\title{
The Efficacy of Retrograde Infusion with LY231617 in a Rat Middle Cerebral Artery Occlusion Model
}

\author{
Nobuhiro Inoue, Y. Lucas Yamamoto, Yasushi Ito, James A. Clemens, Jill K. \\ Panetta and Mirko Diksic
}

\begin{abstract}
Background and Purpose: We examined the efficacy of the antioxidant LY231617 administered five hours following middle cerebral artery (MCA) occlusion in rats. Methods: The treatment was contrived for a two hour interval. Group A $(n=16)$ was left untreated. Group B $(n=16)$ received an intravenous infusion of LY231617. Group $C(n=6)$ received saline $(86 \mu \mathrm{l} / \mathrm{min})$ by retrograde infusion of the cerebral vein (RICV). Group D ( $\mathrm{n}=22)$ was administered LY231617 $(10 \mathrm{mg} / \mathrm{kg} / 2 \mathrm{hr})$ in saline $(86 \mu \mathrm{l} / \mathrm{min})$ by RICV. Local cerebral blood flow with $\left[{ }^{14} \mathrm{C}\right]$-iodoantipyrine and blood-brain transfer constant with ${ }^{14} \mathrm{C}-\alpha$ amino-isobutyric acid were examined. Early ischemic damage was histologically examined with cresyl violet and Luxol fast blue and with triphenyl-tetrazolium chloride. Results: The results revealed a marked increase in local cerebral blood flow (over 600\%, p < 0.01) after RICV with LY231617, with a significant improvement of BBB permeability in rats from group D. Ischemic brain damage measured with Luxol fast blue and triphenyl-tetrazolium chloride methods showed a significant improvement (50-91\%) of ischemic damage in group D, as compared to groups B and C. Conclusion: Retrograde infusion of the cerebral vein with LY231617 resulted in a significant amelioration at seven hours post MCA occlusion.
\end{abstract}

\begin{abstract}
RÉSUMÉ: Efficacité d'une infusion rétrograge de LY231617 chez le rat comme modèle expérimental d'occlusion de l'artère cérébrale moyenne. Introduction: Nous avons évalué l'efficacité du LY231617, un antioxidant, injecté 5 heures après l'occlusion de l'artère cérébrale moyenne $(\mathrm{ACM})$ chez le rat. Méthodes: La durée du traitement était de deux heures. Le groupe $A(n=16)$ n'était pas traité. Le groupe $B(n=16)$ a reçu une infusion intraveineuse de LY231617. Le groupe $C(n=6)$ a reçu du salin $(86 \mu \mathrm{l} / \mathrm{min})$ par infusion rétrograde dans la veine cérébrale (IRVC). Le groupe D ( $\mathrm{n}=22)$ a reçu le LY231617 (10 $\mathrm{mg} / \mathrm{kg} / 2 \mathrm{hrs})$ dans du salin $(86 \mu \mathrm{l} / \mathrm{min})$ par IRVC. Nous avons évalué le flot sanguin cérébral local (FSCL) au moyen de la $\left[{ }^{14} \mathrm{C}\right]$-iodoantipyrine et la constante de transfert hémato-encéphalique au moyen de l'acide $\left[{ }^{14} \mathrm{C}\right]-\alpha$-amino-isobutyrique. Le dommage ischémique précoce a été évalué par coloration histologique au violet de crésyl et au bleu de Luxol (CL) et au chlorure de triphényl-tétrazolium (CTT). Résultats: Nous avons constaté une augmentation marquée du FSCL (plus de 600\%, p<0.01) après l'IRVC au LY231617, accompagnée d'une amélioration significative de la perméabilité de la barrière hémato-encéphalique chez les rats du groupe $\mathrm{D}$.

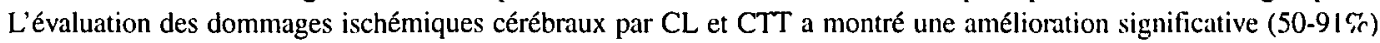
des dommages ischémiques dans le groupe D par rapport aux groupes B et C. Conclusion: Le traitement par IRVC de LY231617 a entrainé une amélioration significative 7 heures après l'occlusion de l'ACM.
\end{abstract}

Can. J. Neurol. Sci. 1996; 23: 175-183

Despite numerous experimental studies for the treatment of acute focal cerebral ischemia, efficacy was limited by the timing of administration of cytoprotective agents either before or less than two hours after occlusion. ${ }^{1-3}$ Clinical trials for the initiation of treatment of early acute stroke revealed that commencement began 1.5 to 5 hours following clinical onset of stroke by an emergency trauma team. ${ }^{4}$ This study further examines the retrograde infusion of a cerebral vein (RICV) as a means of delivering cytoprotective agents with capillary vasodilator more efficiently and selectively to ischemic tissue. ${ }^{5.6,47}$ Our previous study indicated that starting treatment with the $\mathrm{Ca}^{2+}$ antagonist verapamil using RICV three hours after occlusion of the middle cerebral artery (MCAO), resulted in significant improvement in local cerebral blood flow (LCBF) with reduction of ischemic brain damage. ${ }^{7}$ Systemic administration of verapamil in the same model failed to provide any beneficial effect; in fact, treatment was associated with increased blood-brain barrier permeability $(\mathrm{BBB})$ and edema. ${ }^{8}$ In further studies, treatment

From the Neuroisotope Laboratory and Cone Laboratory for Neurosurgical Research Montreal Neurological Institute, McGill University, Montreal (YLY, MD); and Lilly Research Laboratory, Eli Lilly and Company, USA. (JAC, JKP). N.I. wis on leave of absence from Kumamoto University Medical School, Kumamoto, Japan; Y.I. is on leave of absence from Niigata University Medical School, Niigata, Japan .

RECEIVED SEPTEMBER 29, 1994. ACCEPTED IN FINAL FORM MARCH 25, 1996.

Reprint requests to: Dr. Y. Lucas Yamamoto, Director, Neuroisotope Laboratory, Montreal Neruological Institute, 3801 University Street, Room 688, Montreal, Quebec, Canada H3A 2B4 
using RICV with a combination of drugs, such as verapamil, dexamethasone and mannitol resulted in a significant therapeutic effect with treatment initiated five hours following MCA occlusion in rats. ${ }^{8}$

An excess of free radical production has been well documented to have potentially damaging effects on ischemic brain tissue..$^{9-19}$ Recent reports of free radical scavengers or antioxidants indicated that these drugs had a significant beneficial effect on ischemic neuronal damage. Superoxide dismutase has been reported to protect brain cells against focal and global ischemia. ${ }^{20.22}$ Dimethylthiourea and allopurinol were also reported to act as hydroxyl radical scavengers through xanthine oxidase inhibitors. ${ }^{23,24}$ Furthermore, the lipid peroxidation inhibitor, tirilazad mesylate has been a beneficial effect on ischemic neuronal damage, ${ }^{25.26}$ and brain edema. ${ }^{13.26}$ In the studies described above, drugs were given intraperitoneally either before of immediately after vessel occlusion to obtain a beneficial effect. A new antioxidant LY231617 (2,6-bis(1,1dimethylethyl)-4[[1-ethyl)amino]methyl] phenolhydrochloride]) administered intravenously was reported to reduce ischemic damage in a 30 minute and three hour old focal ischemic rat model. ${ }^{12,48}$ LY231617 inhibited iron-dependent lipid peroxidation, attenuated glutamate neurotoxicity and brought about the blockage in arachidonic cascade. ${ }^{12}$

In the present study, a delayed initiation of treatment within a therapeutic time window of five hours after MCAO by RICV with LY231617 is examined. ${ }^{4}$ For evaluation of the efficacy of RICV with LY231617, LCBF, alterations in BBB permeability, as well as extent of ischemic cerebral damage using a direct and indirect methods were examined.

\section{Materials and Methods}

Sixty Sprague-Dawley rats weighing $350-430 \mathrm{~g}$ were fasted overnight with water provided ad libitum before the experiment. All rats had a focal cerebral ischemia brought about by occlusion of the left middle cerebral artery with electrocoagulation of the linticulostriate branches after left subtemporal craniectomy using the modified method of Tamura et al. ${ }^{27}$ The rats were then assigned to four groups labelled $A$ through $D$. The untreated control group $A(A=16)$ was studied for $L C B F$ and BBB permeability, and early ischemic brain damage using direct histopathological methods, cresyl violet and Luxol fast blue (CL). The rats in group $B(B=16)$ were treated for two hours intravenously with LY231617, five hours after the left MCAO. LCBF was examined and ischemic brain damage was analyzed directly using the CL staining method and indirectly using 2,3,5-triphenyl-tetrazolium chloride (TTC) staining. The rats in group $\mathrm{C}(\mathrm{C}=6)$ were treated by $\mathrm{RICV}$ with saline $(86 \mu \mathrm{l} / \mathrm{min})$ at the body temperature of $37^{\circ} \mathrm{C}$ which was started five hours after MCAO for a period of two hours. The rats were examined for ischemic brain damage by indirect measurement of TTC staining. Treatment of group D $(D=22)$ with LY231617 in the saline of the body temperature of $37^{\circ} \mathrm{C}$ as the group $\mathrm{C}$ using retrograde infusion of the cerebral vein (RICV) $(10 \mathrm{mg} / \mathrm{kg} / 2 \mathrm{hr}$ and $86 \mu \mathrm{l} / \mathrm{min})$ was started five hours after MCAO for a period of two hours. The rats in group D were examined for LCBF and BBB permeability. Ischemic brain damage was evaluated directly by histopathological examination by the CL staining method and indirectly by the semiautomated measurement method of TTC. ${ }^{11} \mathrm{C}$-iodoantipyrine
(IAP) (specific activity; $50 \mathrm{mCi} / \mathrm{mmol}$ ) was used for measurement of LCBF and ${ }^{14} \mathrm{C}$ - $\alpha$-aminoisobutyric acid (AIB) (specific activity; $58 \mathrm{mCi} / \mathrm{mmol}$ ) for measurement of the $\mathrm{BBB}$ permeability and 2,3,5-triphenyltetrazolium chloride (TTC) (Sigma Chemical Co., St. Louis, MO., USA) was used for the determination of mitochondrial dehydrogenase activity. Antioxidant LY231617 was provided by the Lilly Research Laboratories, Eli Lilly Co., Indianapolis, Indiana.

Details of the surgical preparation and monitoring of physiological parameters have been previously published. ${ }^{5-8}$ Briefly, anesthesia was induced by inhalation of $2.5-3 \%$ halothane for two to three minutes and maintained by spontaneous respiration with the delivery of $1.0-1.5 \%$ halothane in mixture with room air through a mask. Polyethylene catheters were placed in the femoral artery for monitoring blood pressure, blood gases, hematocrit, blood glucose and radioisotope concentration, and in the femoral vein for administration of radioisotope and drugs.

A dental drill was used to make a small craniectomy in the left temporal bone in all rats. All lenticulostriate branches of the left MCA were electrocoagulated. The left MCA was then occluded proximal to the lenticulostriate branches by a Zen clip (Ohwa Tsusho Ltd,. Tokyo, Japan) and electrocoagulated just distal to the Zen clip using a modified Tamura method. ${ }^{27}$ After occluding the left middle cerebral artery (MCAO) an additional small craniectomy was performed using a dental drill on the left squamous bone just behind the postglenoid foramen in rats of groups $C$ and $D$. The inferior cerebral vein was exposed, and a tapered tip of a polyethylene catheter (PE-10) was cannulated backwards into the inferior cerebral vein to establish unindirectional flow into the ischemic tissue without any perfusion flow into the distal part of the inferior cerebral vein. After completion of the surgical procedure, all rats were immobilized in loose-fitting plaster casts, and halothane was discontinued. Lidocaine hydrochloride was used for local anesthesia of the surgical wounds in all groups. Within one hour after cessation of the general anesthesia, all rats awakened completely.

LY231617 was diluted in normal saline and infused at a rate of $86 \mu \mathrm{l} / \mathrm{min}$ into the femoral vein of rats in group $\mathrm{B}$. The rats in group $\mathrm{C}$ received body temperature $\left(37^{\circ} \mathrm{C}\right)$ of saline $(86 \mu \mathrm{l} / \mathrm{min})$ through the inferior cerebral vein using an infusion pump (IVAC 710 syringe pump, IVAC Corp., San Diego, California). The rats in group D were given LY231617 in the body temperature $\left(37^{\circ} \mathrm{C}\right)$ of saline $(86 \mu \mathrm{l} / \mathrm{min})$ through the inferior vein using an IVAC infusion pump. All rats except for the untreated control group were infused over a period of two hours following five hour focal ischemia. During the two hours of RICV, the infusion pressure of saline and LY231617 solution was monitored constantly and kept at $150 \mathrm{mmHg} .{ }^{6}$ Physiological parameters, such as systemic blood pressure, blood gases, hematocrit, and blood glucose were measured regularly. The body temperature was maintained at $37 \pm 0.5^{\circ} \mathrm{C}$ with a heat lamp.

\section{Measurement of LCBF}

We measured the LCBF in ten rats from each of Groups $A, B$ and $\mathrm{D}$ using $\left[{ }^{14} \mathrm{C}\right]$-iodoantipyrine $\left({ }^{14} \mathrm{C}\right.$-IAP) at the end of the treatment. $30 \mu \mathrm{Ci}{ }^{14} \mathrm{C}$-IAP in $1 \mathrm{ml}$ of normal saline was injected into the femoral vein using a Sage 351 syringe pump (Orion Research Incorp., Boston, MA) for a period of one minute. Arterial blood samples ( $20 \mu \mathrm{l}$ each) were collected at five-second intervals after the start of injection of ${ }^{14} \mathrm{C}$-IAP. At the end of the 
one minute infusion the animals were decapitated. The brains were removed and immediately frozen in liquid Histo Freeze (Fisher Scientific., Nepean, Ontario, Canada). The brains were sliced into $20 \mu \mathrm{m}$ sections in a cryostat $\left(-22^{\circ} \mathrm{C}\right)$ and each section was mounted on a microscopic cover glass and rapidly dried on a hot plate for autoradiography. The mounted brain sections were exposed on Kodak SB-5 films (Rochester, New York) for one week with $\left[{ }^{14} \mathrm{C}\right]$ standards (American Radiolabelled Chemicals Inc., St. Louis, Missouri). The densitometric measurements were made with a digital analyzer (The Image Calculator, McGill University, Canada). The mean values of the $\left[{ }^{14} \mathrm{C}\right]$ tissue radioactivities were obtained from each autoradiogram by measuring the optical density of three regions of one locus in three consecutive brain slices as designated by the rat brain atlas. ${ }^{28}$ The radioactivity of $\left[{ }^{14} \mathrm{C}\right]$ was measured using a 1219 Rackbeta liquid scintillation counter (Wallace Oy, Turku, Finland). LCBF was calculated using the operational equation described by Sakurada et al. $1978 .^{36}$ The anatomical identifications of each area was made from the atlas of Paxinos and Watson. ${ }^{28}$

\section{Quantitative Assessment of Early Ischemic Brain Damage}

\section{A. Direct Histopathological Method using Cresyl Violet and Luxol Fast Blue (CL)}

Seven frozen coronal tissue sections were taken from the ten rats used for LCBF measurement of groups A, B and D. The coronal tissue was sliced at $20 \mu \mathrm{m}$ thickness adjacent to that used for the ${ }^{14} \mathrm{C}$-IAP autoradiograms at $1.28 \mathrm{~mm}$ intervals beginning at a level $3.2 \mathrm{~mm}$ anterior to the occipital pole. These sections were dried, then fixed in $10 \%$ formaldehyde solutions overnight and stained by a combined method of cresyl violet and Luxol fast blue. ${ }^{29}$ The areas of unstained ischemic damage were manually outlined on the digitized images of seven equally spaced coronal sections using a digital image analysis system (The Image Calculator, McGill University, Montreal, Canada). Any indistinct border of ischemic cerebral damage was examined under the light microscope for neuronal ischemic damage as described by Osborne et al. 1987.29 The total volumes of ischemic damage were determined by the integration of areas with distance between neighboring sections.

\section{B. Indirect Method Using Semiautomated Analysis of TTC Infusion}

In separate experiments, a total of 18 rats, six from each of groups $B, C$ and D were subjected to further quantitative examination of early cerebral ischemic damage by a more objective method using the TTC staining technique. The staining action of tetrazolium salts was based on the presence of active dehydrogenases in mitochondria. ${ }^{31}$ Tissue with a normal level of enzyme activity was stained deep red, where as the ischemic damaged tissue was unstained owing to lack of the mitochondrial enzyme activity. ${ }^{30}$ The intracardiac infusion method of TTC was established to be superior to the immersion method. ${ }^{31}$ The $2 \%$ solution of TTC was prepared with $37^{\circ} \mathrm{C}$ phosphate buffered saline (pH 7.4) immediately before use. Seven hours after the MCAO, anesthesia was induced by inhalation of $2-3 \%$ halothane and maintained by spontaneous respiration. An 18-gauge needle was passed through the left ventricle to the proximal ascending aorta under thoracotomy. The right atrium was incised, the descending aorta was clamped, and $300 \mathrm{ml}$ of the TTC solution was immediately infused by gravity flow through the needle for 30 minutes. During infusion, the temperature was maintained at $37^{\circ} \mathrm{C}$ using a heat lamp. After infusion for 30 minutes, the brains were immediately removed and fixed in $10 \%$ formalin solution overnight. This intracardiac perfusion of TTC staining method has been found to be more sensitive and reliable technique for detection of the early ischemic damaged cerebral tissue rather than the intravenous TTC staining method. ${ }^{31.34}$ After fixation, the TTC-stained brain was sliced coronally using a thickness of $2 \mathrm{~mm}$. The coronal slices were taken at $3,5,7,9$ and $11 \mathrm{~mm}$ from the occipital pole. The volume of ischemic damage were taken from all five coronal sections of color slide and measured by a digital imaging analysis system (MCID System; Imaging Research Inc., Ontario, Canada) adopting a semiautomated method described by Swanson et al. ${ }^{18}$ The low optimal densities [mean value minus three time of standard deviation (less than $99.7 \%$ probability)] in the cortical gray matter and basal ganglia, excluding the white matter in the non-ischemic hemisphere were determined for each section by visual inspection and by automated densitometric measurement. These optical densities were then used as the threshold values for normal gray matter in the non-ischematic hemisphere by the image analysis system. These thresholds were established for each section to control for any variation of staining intensity or thickness. The areas of optical density greater than the threshold values were automatically measured by the image analysis system in the ischemic cerebral hemispheres of each section (Figure 4A and B). The volumes were calculated by multiplying each sum by the distance between sections. The volumes of the ischemic damaged tissue in the ischemic hemisphere were expressed as a percentage of the volume of the structures in the non-ischemic hemispheres.

$A_{D}(\%)=(A N-A I) / A N \times 100$

$A_{D}=$ percent of volume of ischemic damaged tissue in the ischemic cerebral hemisphere

$\mathrm{A} \ell=$ volume of the non-ischemic hemisphere

$\mathrm{AI}=$ volume of above the threshold tissue in the ischemic cerebral hemisphere

The direct measurement of early ischemic damage by the $\mathrm{CL}$ method was often associated with an overestimation of ischemic damage due to brain edema and swelling in the seven hour old focal ischemia. This artifact could be reduced by indirect, semiautomated analysis with TTC which was based on measured volumes of non damaged tissue in the ischemic hemisphere. ${ }^{32}$

\section{Measurement of Blood-Brain Transfer Constant (Ki)}

We employed the quantitative autoradiographic method developed by Blasbert et al. ${ }^{33}$ to study the cerebral microvascular permeability in six rats from each of groups A and D. Six hours and 29 minutes after MCAO (30 minutes before the termination of the experiments), $30 \mu \mathrm{Ci}$ of ${ }^{14} \mathrm{C}$-AIB in $1 \mathrm{ml}$ of normal saline was injected into the femoral vein using the Sage 351 syringe pump for a period of one minute. $50 \mu \mathrm{l}$ arterial blood samples were drawn at $0.25,0.5,1,2,3,5,7.5,10,15$, 20,25 and 30 minutes after the start of injection of ${ }^{14} \mathrm{C}$-AIB and immediately centrifuged. $20 \mu \mathrm{l}$ of plasma was then pipetted from each sample into counting vials. The rats were decapitated seven hours after MCAO and the brains were removed and immediately frozen. The brain sections were made with the 
similar autoradiographic method as for LCBF measurement. Autoradiograms were exposed for a period of three weeks to the SB-5 films with ${ }^{14} \mathrm{C}$-standards. The densitometrical analysis of autoradiograms was performed with the similar procedures as for LCBF measurement. The $(\mathrm{Ki})$ s for each locus were calculated from the ${ }^{14} \mathrm{C}$ tissue concentration obtained from the autoradiograms and the ${ }^{14} \mathrm{C}$ arterial plasma concentration-time integral. ${ }^{7}$

\section{Statistical Analysis}

All data were expressed as mean \pm standard deviation. The statistical analysis of all data was performed using one-way analysis of variance (ANOVA), followed by Tukey's intergroup comparison test. A p-value $<0.05$ was considered significant.

\section{Results}

\section{Physiological Data}

In all rats, blood pressure, blood gases, body temperature, hematocrit and blood glucose concentration were stable and did not change significantly during the MCAO nor during the systemic infusion or RICV of LY231617 (10 mg/kg/2hours).

\section{Local Cerebral Blood Flow}

The LCBF of the three groups is summarized in Table 1 and
Figure 1. The LCBF of each cortical and subcortical structure in the ischemic cerebral hemisphere of rats in group D were significantly increased (sensorimotor cortex: over $358 \% \mathrm{p}<0.01$, anterior parietal cortex: over $680 \%, \mathrm{p}<0.01$, posterior parietal cortex: over $286 \%, \mathrm{p}<0.01$, caudate nucleus: over $316 \%$, $\mathrm{p}<0.01$; Table 1) compared to corresponding areas in groups $A$ and $B$ (Figure 1). There was no significant difference of LCBF in the ischemic cerebral hemisphere in group B as compared to group A (Table 1).

\section{Early Ischemic Brain Damage}

\section{A. Direct Measurement by the CL Method}

In the quantitative volumetric measurement of early ischemic brain damage by the direct method using cresyl violet and Luxol fast blue, the rats in group $D$ showed a significant reduction of over $31 \%,<0.01$ (Table 2; Figure 1) in the total volume $\left(\mathrm{mm}^{3}\right)$ of the ischemic hemisphere $(166.8 \pm 6.7$ to $102.4 \pm 9.3, \mathrm{p}<0.01)$, at sensorimotor level (over $34 \%$ reduction; $p<0.01$ ), at anterior parietal level ( $42 \%$ reduction; $\mathrm{p}<0.01$ ), and at posterior parietal level $(56 \%$ reduction; $\mathrm{p}<0.01)$ as compared with rats in groups $\mathrm{A}$ and B. Rats in group B showed no significant difference in total volume of ischemic damage as compared to group A (Table 2).

\section{B. Indirect Measurement by TTC Method}

In Figure 2A, B and C, the TTC staining patterns are shown

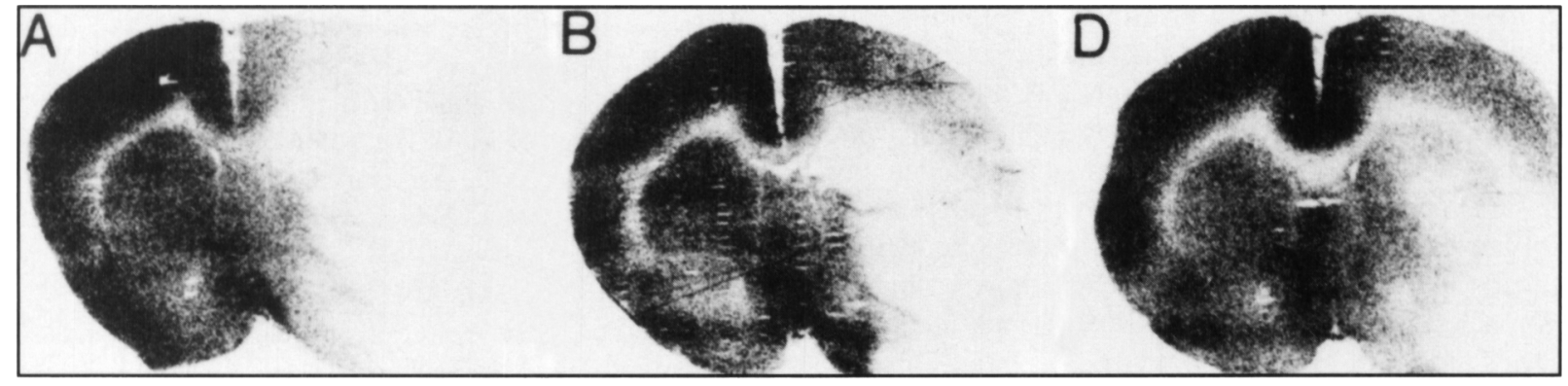

Figure IA,B,C: Autoradiographic images of ${ }^{14} \mathrm{C}$-iodoantipyrine in a coronal section of sensorimotor cortex and caudate nucleus region. Retrograde infusion of the cerebral vein $(R / C V)$ with $L Y 231617$ Group $(D)$ showed marked improvement of $L C B F$ in the ischemic cortical and subcortical areas as compared to that of untreated $(A)$ and LY2316I7 administered intravenously $(B)$.

Table 1: Changes in LCBF Found After Starting Treatment Five Hours After MCAO for a Period of Two Hours.

\begin{tabular}{|c|c|c|c|c|c|c|}
\hline \multirow{2}{*}{$\begin{array}{l}\text { Group } \\
\text { Structure }\end{array}$} & \multicolumn{2}{|c|}{$\begin{array}{c}\text { Group A } \\
\text { (Untreated) } \\
(\mathbf{m l} / \mathbf{1 0 0 g} / \mathbf{m i n}) \\
(\mathbf{n}=\mathbf{1 0})\end{array}$} & \multicolumn{2}{|c|}{$\begin{array}{c}\text { Group B } \\
\text { (IV with LY231617) } \\
\text { (ml/100g/min) } \\
(\mathrm{n}=10)\end{array}$} & \multicolumn{2}{|c|}{$\begin{array}{c}\text { Group D } \\
\text { (RICV with LY231617) } \\
(\mathrm{mL} / 100 \mathrm{~g} / \mathrm{min}) \\
(\mathrm{n}=10)\end{array}$} \\
\hline & Left & Right & Left & Right & Left & Right \\
\hline Frontal Cortex & $30 \pm 7$ & $131 \pm 5$ & $42 \pm 7$ & $115 \pm 7$ & $55 \pm 7$ & $115 \pm 8$ \\
\hline Sensorimotor Cortex & $7 \pm 2$ & $124 \pm 5$ & $12 \pm 3$ & $110 \pm 7$ & $43 \pm 7 \#$ & $112 \pm 9$ \\
\hline \multicolumn{7}{|l|}{ Caudate } \\
\hline Lateral & $1 \pm 0$ & $122 \pm 5$ & $8 \pm 3$ & $108 \pm 7$ & $25 \pm 10^{*}$ & $107 \pm 9$ \\
\hline Medial & $11 \pm 3$ & $122 \pm 6$ & $18 \pm 5$ & $101 \pm 7$ & $70 \pm 8 \#$ & $102 \pm 9$ \\
\hline $\begin{array}{l}\text { Postero-Lateral Portion } \\
\text { of Caudo-Putamen }\end{array}$ & $2 \pm 1$ & $109 \pm 5$ & $6 \pm 2$ & $100 \pm 6$ & $12 \pm 3$ & $93 \pm 10$ \\
\hline
\end{tabular}

Values are started as the mean \pm standard deviation

*: $p<0.05$ significant difference from the Group A by ANOVA

\#: $p<0.01$ significant difference from the Group B by ANOVA 
Table 2: Direct Measurement of Ischemic Damage Using the CL Method in Five Hour Old Focal Ischemia Following Various Treatments.

\begin{tabular}{|c|c|c|c|}
\hline Location & $\begin{array}{c}\begin{array}{c}\text { Group A } \\
\text { (Untreated) }\end{array} \\
(\mathbf{n = 1 0})\end{array}$ & $\begin{array}{c}\text { Group B } \\
\text { (IV with } \\
\text { LY231617) } \\
(\mathbf{n}=10)\end{array}$ & $\begin{array}{c}\text { Group D } \\
\text { (RICV with } \\
\text { LY231617) } \\
(\mathbf{n}=10)\end{array}$ \\
\hline $\begin{array}{l}\text { Sensorimotor Level } \\
\left(\mathrm{mm}^{2}\right)\end{array}$ & $36.9 \pm 1.6$ & $32.3 \pm 2.5$ & $21.2 \pm 2.8 \#$ \\
\hline $\begin{array}{l}\text { Anterior Parietal Level } \\
\left(\mathrm{mm}^{2}\right)\end{array}$ & $18.8 \pm 1.6$ & $18.3 \pm 1.7$ & $10.9 \pm 1.2 \#$ \\
\hline $\begin{array}{l}\text { Posterior Parietal Level } \\
\left(\mathrm{mm}^{2}\right)\end{array}$ & $14.1 \pm 1.3$ & $12.7 \pm 1.9$ & $5.6 \pm 1.2 \#$ \\
\hline $\begin{array}{l}\text { Total Ischemic Damage } \\
\text { Volume }\left(\mathrm{mm}^{2}\right)\end{array}$ & $166.8 \pm 6.7$ & $148.5 \pm 12.8$ & $102.4 \pm 9.3 \#$ \\
\hline $\begin{array}{l}\text { Values are mean } \pm \text { stand } \\
\#: p>0.01 \text { significant di } \\
C L \text { - cresyl violet and } L\end{array}$ & $\begin{array}{l}\text { d deviation } \\
\text { erence betw } \\
\text { ol fast blue }\end{array}$ & $\begin{array}{l}\text { iroup } \\
\text { ng }\end{array}$ & VA \\
\hline
\end{tabular}

at the sensorimotor level of each of groups B, C and D. At the sensorimotor level where the ischemic damage was at its maximum in the subcortical part of the striatum, a significant and, marked reduction of ischemic damage tissue was observed in both cortical (over $76 \%, \mathrm{p}<0.005)$ and striatal $(91 \%, \mathrm{p}<$ 0.005 ) areas in group $\mathrm{D}$, as compared to groups B and C. A total volume of ischemic damaged tissue was also significantly reduced to $52-57 \%$, $(\mathrm{p}<0.005)$ in group $\mathrm{D}$ as compared to group B (Table 3). This indirect, semiautomated analysis of ischemic damaged tissue eliminates the potential error and bias inherent in the manually delineating method of direct histopathological measurement using CL (Figure $4 \mathrm{~A}$ and $\mathrm{B}$ ).

Comparison of direct and indirect methods indicated that the measurement of a total volume of ischemic damaged tissue by the direct histological analysis of CL was over estimated by over $25 \%$ due to artifacts from the brain edema.

\section{Blood-Brain Transfer Constant (Ki)}

$\mathrm{Ki}$ values of $\mathrm{BBB}$ permeability changes were sumarized in Table 4 and Figure 3 . In comparison of $\mathrm{Ki}$ values between

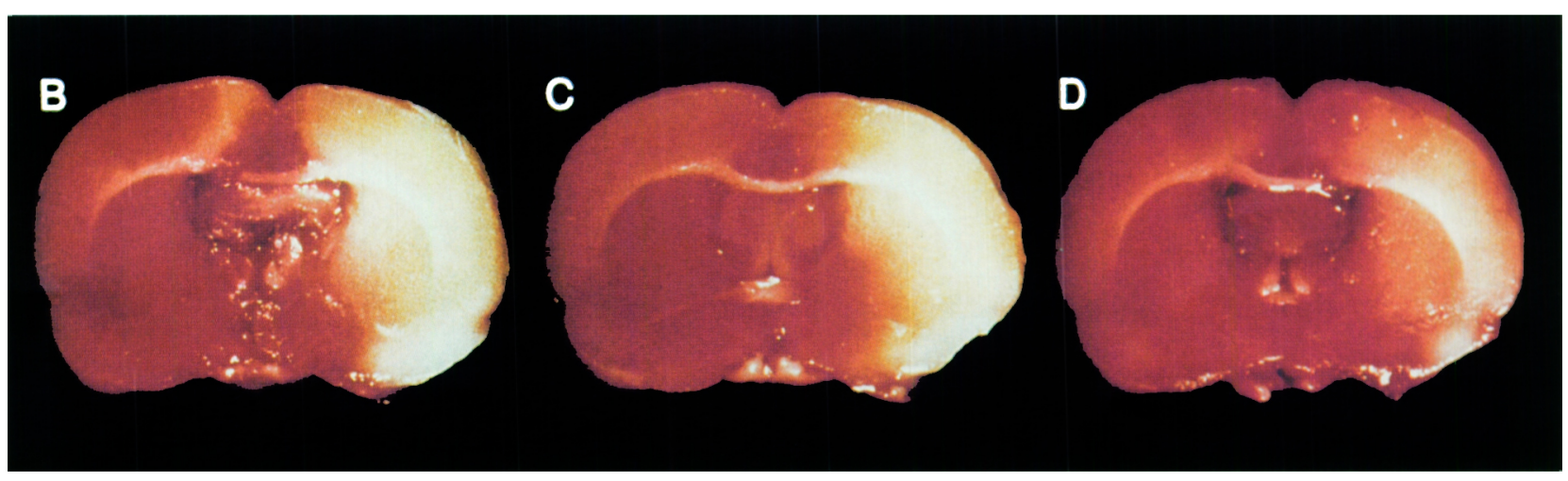

Figure 2A,B,C: Coronal section of the sensorimotor cortex and caudate nucleus region, following intracardiac infusion of TTC. Intravenous infusion of LY231617: Group B showed 44.3\% of cerebral tissue damaged (unstained with TTC) in the cortical area and 30.8\% of tissue damaged in the striatum area of the ischemic hemisphere as compared to the non-ischemic hemisphere $(B)$. Retrograde infusion of the cerebral vein (RICV) with saline: Group $C$ showed $40.9 \%$ of cerebral tissue damaged in the cortical area and $31.4 \%$ of tissue damaged in the striatum area of the ischemic hemisphere as compared to the non-ischemic hemisphere (C). Retrograde infusion of the cerebral vein (RICV) with LY231617: group D showed only 11.7\% of cerebral tissue damaged in the cortical area and $2.9 \%$ of tissue damaged in the striatum area of the ischemic cerebral hemisphere as compared to the non-ischemic hemisphere (D). There is a significant amelioration of cerebral tissue damage $(52-57 \%, p<0.005 ; p<0.005)$ in Group D rats as compared to Groups $B$ and $C$ rats.

Table 3: Indirect TTC Analysis of Ischemic Damaged Tissue in Five Hour Old Focal Ischemia Following Various Treatments.

\begin{tabular}{|c|c|c|c|}
\hline Damaged Tissue Volume (\%) & $\begin{array}{c}\text { Group B } \\
\text { (IV with LY231617) } \\
(n=6)\end{array}$ & $\begin{array}{c}\text { Group C } \\
\text { (RICV with Saline) } \\
(n=6)\end{array}$ & $\begin{array}{c}\text { Group D } \\
\text { (RICV with LY231617) } \\
(\mathrm{n}=6)\end{array}$ \\
\hline
\end{tabular}

At the Sensorimotor Level

$$
44.3 \pm 4.3
$$

Cortical Area

$$
30.8 \pm 7.3
$$$$
31.4 \pm 6.0
$$

Striatum Area

Total Volume

$22.5 \pm 2.6$

$25.1 \pm 2.6$
$11.7 \pm 4.6$

$(-76 \%, \mathrm{p}<0.005$; against Group C) $(-78 \%, \mathrm{p}<0.001$; against Group B)

$2.9 \pm 1.3$

$(-91 \%, p<0.001$, against Group C) $(-91 \%, p<0.005$, against Group B) $10.9 \pm 1.5$

$(-57 \%, p<0.005$, against Group $C)$ $(-52 \%, p<0.005$, against Group B)

Mean \pm standard deviation $\left(\mathrm{mm}^{2} \pm \mathrm{SD}\right)$ 


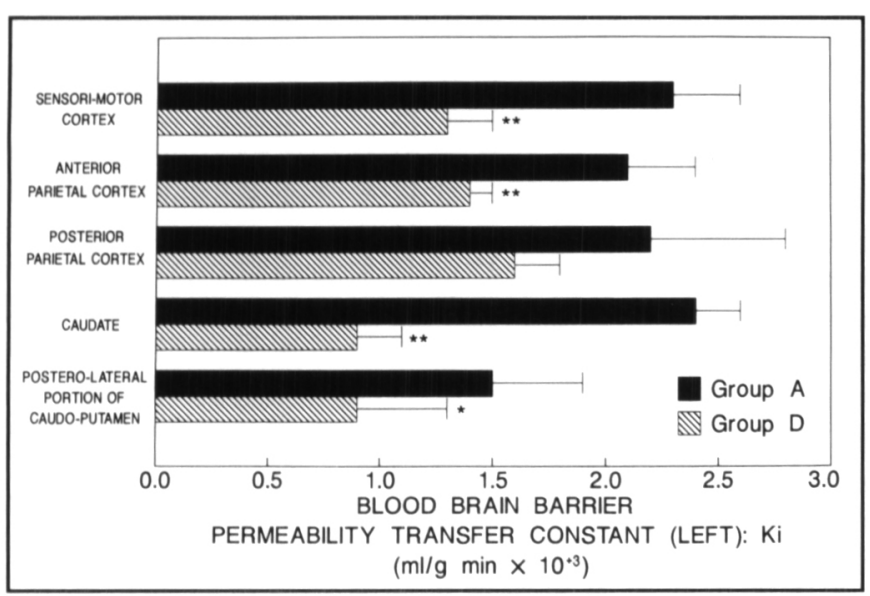

Figure 3: Histograms comparing blood-brain barrier permeability (Ki) values in ischemic cortical and subcortical areas. Retrograde infusion of the cerebral vein (RICV) with LY2316I7 (Group D) showed a significant reduction of changes in $B B B$ permeability as compared to that of untreated animals (Group A). Columns and bars represent the mean \pm standard deviation. *: $p<0.05, * *: p<0.01$ significant difference from control group by one way ANOVA. ischemic hemispheres of groups $\mathrm{A}$ and $\mathrm{D}$, there was a significant reduction of the $\mathrm{Ki}$ values in the cortices (sensorimotor cortex: $43 \% \mathrm{p}<0.01$ anterior parietal cortex: $33 \% \mathrm{p}<0.01$ ), and subcortical areas (caudate nucleus: $55 \% \mathrm{p}<0.01$, posterolateral portion of caudoputamen: $40 \% \mathrm{p}<0.05$ ) in group D. Comparison of $\mathrm{Ki}$ values between ischemic hemisphere and non-ischemic hemisphere in Group A showed a significant increase of $\mathrm{Ki}$ values that was also observed in the ischemic cortices (sensorimotor cortex: 43\% $\mathrm{p}<0.05$, anterior parietal cortex: $31 \% \mathrm{p}<0.01$ ) and subcortical area (caudate nucleus: $53 \% \mathrm{p}<0.01$ ) as compared to those of the non-ischemic hemisphere indicating that LY231617 has a protection and repairability of $B B B$ function in the five hour old ischemic cerebral tissue.

\section{Discussion}

LY231617 (2,6 - bis (1,1-dimethylethyl)-4-[[(1-ethyl)amino] methyl] phenol hydrochloride]) has the structure of butylated hydroxytoluene which has been known to have antioxidant activity. LY231617 and its related compounds were recently reported as having the following effects: inhibiting iron-depen-
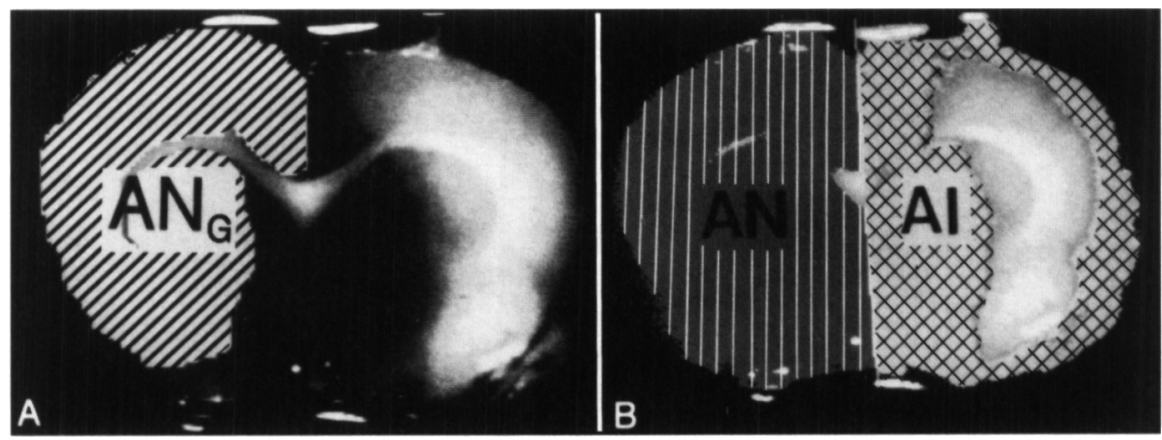

Figure 4A: The diagram shows a coronal section at the sensorimotor and caudate nucleus level, seven hours after occlusion of the right middle cerebral artery, following the intracarotid infusion of TTC. The $A N_{G}$ is the lowest optical density value (minus mean value $x 3$ standard deviation value) in the grey matter and basal ganglia, excluding the white matter in the non-ischemic hemisphere. This was determined for each section by the automated densitric measurement as the lowest threshold values (ANG, IIII in Figure $4 A$ ) for recognition of normal grey and basal ganglia. These normal lower thresholds $\left(A N_{G}\right)$ were established for each section to control for varying section thickness and staining intensity. B: The area of non-ischemic damaged tissue with optical density greater than the threshold value was measured in both ischemic cerebral hemisphere $\left(A_{N} \#\right) . A_{D}(\%)=(A N-A I) / A N$ $x A_{D}$ in the percent volume of non-ischemic damaged tissue in the ischemic hemisphere.

Table 4: Comparison of Blood - Brain Transfer Rate Constant in the Control Group and RICV with LY231617.

$\begin{array}{cc}\text { Group A } & \text { Group D } \\ (\text { Untreated }) & (\text { RICV with LY231617) } \\ \left(\times 10^{+3} \mathrm{ml} / \mathrm{g} / \mathrm{ml}\right) & \left(\mathrm{x10}^{+3} \mathrm{ml} / \mathrm{g} / \mathrm{ml}\right) \\ (\mathrm{n}=6) & (\mathrm{n}=6)\end{array}$

\begin{tabular}{|c|c|c|c|c|}
\hline Structure & Left & Right & Left & Right \\
\hline Sensorimotor Cortex & $2.3 \pm 0.3 @$ & $1.6 \pm 0.3$ & $1.3 \pm 0.2 * *$ & $1.2 \pm 0.3$ \\
\hline Anterior Parietal Cortex & $2.1 \pm 0.3 @$ & $1.6 \pm 0.3$ & $1.4 \pm 0.1 @ * *$ & $1.1 \pm 0.2$ \\
\hline Posterior Parietal Cortex & $2.2 \pm 0.6$ & $1.6 \pm 0.2$ & $1.6 \pm 0.2 @ \times x$ & $1.2 \pm 0.2$ \\
\hline Caudate Lateral & $2.4 \pm 0.2 @ @$ & $1.2 \pm 0.3$ & $0.9 \pm 0.2 * *$ & $0.8 \pm 0.1$ \\
\hline Caudate Medial & $2.0 \pm 0.2 @ @$ & $1.3 \pm 0.2$ & $0.9 \pm 0.2^{* *}$ & $0.9 \pm 0.2$ \\
\hline Post. Lat. of C.P. Complex & $1.5 \pm 0.4$ & $1.1 \pm 0.3$ & $0.9 \pm 0.4^{*}$ & $0.7 \pm 0.1$ \\
\hline
\end{tabular}

Values are expressed as the mean \pm standard deviation

@@@: $\mathrm{p}<0.05 ; \mathrm{p}<0.01$, significant difference between non-ischemic and ischemic hemisphere in the Groups A and D by ANOVA; ${ }^{x} \mathrm{p}<0.05 ;{ }^{x \times}$ $\mathrm{p}<0.01$, significant difference in the ischemic hemisphere between Groups A and D by ANOVA 
dent lipid peroxidation, attenuating glutamate neurotoxicity, blocking enzymes of the arachnoid cascade and ameliorated neuronal damage in vitro and in vivo. ${ }^{11.12}$ This agent has an advantage of being water soluble and easily penetrates the BBB. ${ }^{11.12}$ This agent also has a potent vasodilating effect and repairability of $\mathrm{BBB}$ function.

In the previous study, we observed a significant worsening of $\mathrm{BBB}$ permeability due to the vasodilating effect of RICV with verapamil in the seven hour old ischemic cortical areas. The values of $\mathrm{BBB}$ transfer constant $(\mathrm{Ki})$ was significantly improved similar to the non-ischemic cortical areas with RICV with a combination of verapamil, mannitol and dexamethasone. ${ }^{8}$ A comparison of beneficial effects between RICV with LY231617 alone and RICV with three combined drugs indicates that the antioxidant LY231617 alone resulted in the greater improvement of ischemic damaged tissue than the therapy involving the combination of all three drugs. ${ }^{8}$ The body temperature $\left(37^{\circ} \mathrm{C}\right)$ of saline was used in groups $\mathrm{C}$ and D with the same infusion rate, therefore, hypothermic effects were not expected a difference of therapeutic effect between group C and group D. We have studied the regional cerebral blood flow using oxygen15 labelled $\mathrm{H}_{2}{ }^{15} 0$ with high resolution positron emission tomography (PC-2048 system) during three to five hours after the occlusion of the left middle cerebral artery in Rhesus monkeys (Appendix 1). ${ }^{46}$ This study indicates that CBF was further reduced during RICV with saline, but RICV with LY231617 was significantly increased in the same monkeys (unpublished) ${ }^{46}$ due to potent vasodilating effect of LY231617 with marked vasodilating effect to the ischemic tissue in which reduced capillaries resist and produce "sinking effect" to the ischemic capillary to encourage the development of collateral flow from the non-occluded cerebral vessels and specific higher concentration (3 to 10 times) of LY231617 to the ischemic tissue. ${ }^{47}$

The accurate determination of the extent of ischemic damage in the ischemic cerebral hemisphere was essential for the assessment of therapeutic intervention and for the evaluation of therapeutic efficacy. Therefore, we used both a direct histopathological method using a CL staining technique and an indirect semiautomated method ${ }^{18}$ using the TTC infusion technique to delineate accurately and objectively the areas and volumes of ischemic damage following various therapeutic procedures. The reliability of TTC staining as a marker of ischemic damage had been evaluated by comparing light and electron microscopic findings by several investigations ${ }^{30.31 .34}$ and it was found that TTC-staining could detect early ischemic damage and accurately delineate the extent of an ischemic area in over six hour old focal cerebral ischemia by intracardiac perfusion of TTC. ${ }^{31,34}$ The indirect, semiautomated method with intracardiac perfusion of TTC provided an accurate and objective measurement of size and volume of early ischemic brain damage, particularly when the damaged tissue was compromised by edema and swelling. ${ }^{18,32}$ This indirect semiautomated measurement of ischemic damaged volume, based on the measurement of residual non-damaged tissue in the ischemic hemisphere, eliminated the artifacts produced by brain edema and swelling in the ischemic damaged tissue. ${ }^{18.32}$ The difference between the volume of the ischemic damage determined by both methods, indicated that the indirect method greatly reduced or eliminated error from brain swelling and added objectiveness to the analysis. Therefore, the present study indicated that treat- ment using retrograde infusion of the cerebral vein (RICV) with LY231617 (Group D) provided a significant improvement of ischemic brain damage as compared with intravenous treatment (Group B) or retrograde infusion of the cerebral vein (RICV) with saline (Group $C$ ) in the seven hour old focal ischemic model.

The dose limiting toxicity of LY231617 is hypotension. Intravenous and retrograde infusion of the cerebral vein (RICV) infused at a rate of $10 \mathrm{mg} / \mathrm{kg}$ per two hours did not result in any significant reduction of the mean arterial blood pressure (MAPB). However, a dose of $20 \mathrm{mg} / \mathrm{kg}$ over a similar period resulted in a significant reduction of MABP with both intravenous and retrograde infusion of the cerebral vein (RICV). Therefore, a dose of $10 \mathrm{mg} / \mathrm{kg} / 2 \mathrm{hr}$ was utilized for this study.

A peroxidative mechanism has been implicated as one of the prime detrimental factors in ischemic neuronal and vascular damages following cerebral ischemia. ${ }^{1,34,35}$ Endothelial cells of brain microvessels were known to be primary targets for free radical injury, ${ }^{10,13,16,17.37}$ because of the high concentration of xanthine oxidase, nitric oxide synthase. ${ }^{30.45}$ Oxygen radical activities also cause severe vascular damage with disruption of BBB permeability and a resulting vasogenic edema. ${ }^{10,17,25,38,44}$ Free radical scavengers or antioxidants were reported to prevent these cascades in endothelial cells to preserve capillary function. ${ }^{21,23,24,26,38,39}$ In this study, the blood-brain transfer constant (Ki) was found to be significantly increased in the ischemic cortex (30 to $40 \%$ ) and caudate nucleus (50 to 100\%) as compared to the non-ischemic hemisphere in group $\mathrm{A}$. The Ki values were markedly improved to non-significant degree between ischemic and non-ischemic hemispheres of both cortical and subcortical areas in group D. Therefore, there was significant improvement of BBB permeability disruption following retrograde infusion of the cerebral vein (RICV) with LY231617 treatment. There are limited reports of efficacy of the free radical scavengers on the $\mathrm{LCBF}$ after ischemia via systemic administration, the majority of which failed to reveal any significant improvement of LCBF except for these areas where collateral circulations existed. ${ }^{14,20,21,34,40}$ Recent reports using free radical scavengers delivered intravenously for models of permanent $\mathrm{MCAO}$ indicated a significant efficacy on brain edema. These improvements were only obtained when these drugs were administered systemically shortly before or less than one hour after MCAO. 14,26,39,41

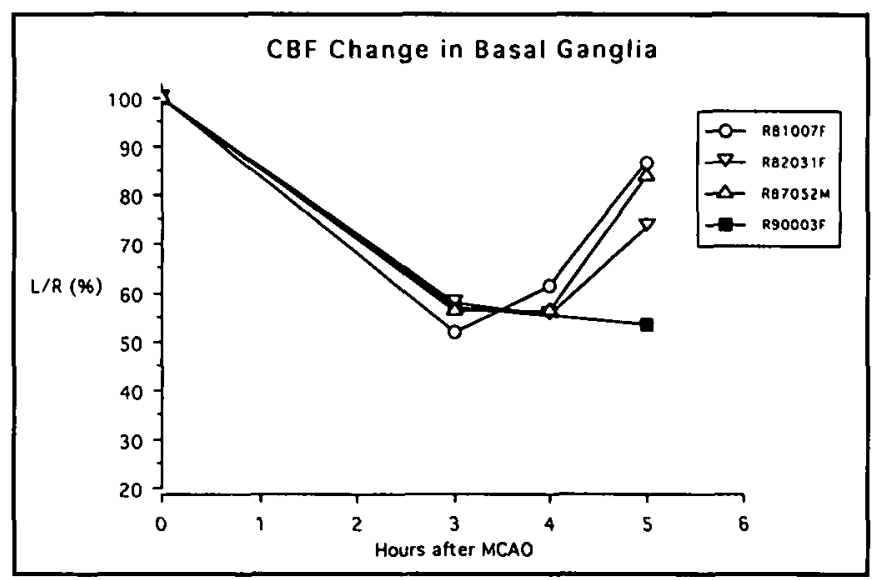

Appendix $1^{46}$ 
A new antioxidant, LY231617, was recently reported to cause significant inhibition of iron-dependent lipid peroxidation, blocking glutamate neurotoxicity and reducing oxidative damage resulting from hydrogen peroxidation. ${ }^{12}$ Inhibition of free radical activities by antioxidant LY231617 possibly plays an important part in the dramatic improvement of LCBF, BBB permeability, and ischemic brain damage in both ischemic cortical, as well as subcortical areas, by the retrograde infusion of the cerebral vein (RICV) delivery method. Thus the treatment using retrograde infusion of the cerebral vein (RICV) with LY231617 is a single agent capable of ameliorating and preventing various ischemic damaging mechanisms in the ischemic cortical and subcortical areas related to abundant collaterals. ${ }^{42}$

The retrograde infusion of the cerebral vein (RICV) is a minor neurosurgical intervention without any alteration of intracranial pressure ${ }^{43}$ and minimum disturbance to the general cerebral venous circulation due to the abundance of collateral channels among the cerebral venous system. Using this minor neurosurgical procedure of retrograde infusion of the cerebral vein (RICV) with antioxidant, we can expect to achieve a significant improvement of focal ischemia even five hours after, in the focal ischemic model in rats.

\section{ACKNOWLEDGEMENTS}

The authors thank Mrs. Janet Arts for her technical assistance. This study was supported by Grant MT-3174 and University-Industrial Grant-11096 from the Medical Research Council of Canada.

\section{REFERENCES}

1. Hall ED, Travis MA. Inhibition of arachidonic acid-induced vasogenic brain edema by the non-glucocorticoid 21 -aminosteroid U74006F. Brain Res 1988a; 451: 350-352.

2. Hossmann KA. Calcium antagonist for the treatment of brain ischemia: a critical appraisal. In: Krieglstein J, ed. Pharmacology of Cerebral Ischemia. Stuttgart, Wissenschaftliche Verlagsgesellschaft, 1988: 53-63.

3. Morikawa E, Ginsbert MD, Dietrich WD, Duncan RC, Busto R. Postischemic (S)-Emopamil therapy ameliorates focal ischemic brain injury in rats. Stroke 1991; 22: 355-360.

4. Barsan WG, Brott TG, Olinger CP, Marlar JR. Early treatment for acute ischemic stroke. Ann Intern Med 1989; 111: 449-451.

5. Ueda T, Yamamoto YL, Takara E, Diksic M. Tolerance of the cerebral venous system to retrograde perfusion pressure in focal cerebral ischemia in rats. Stroke 1989a; 20: 378-385.

6. Ueda T, Yamamoto YL, Diksic M. Transvenous perfusion of the brain with verapamil during focal cerebral ischemia in rats. Stroke 1989b; 20: 501-506.

7. Hosaka T, Yamamoto YL, Diksic M. Efficacy of retrograde perfusion of the cerebral vein with verapamil after focal ischemia in rat brain. Stroke 1991; 22; 1562-1566.

8. Shimauchi M, Yamamoto YL. Effects of retrograde perfusion of the brain with combined drug therapy after focal ischemia in rat brain. Stroke 1992; 23: 1805-1811.

9. Beckman JS, Liu TH, Hogan EL, et al. Evidence for a role of oxygen radicals in cerebral ischemic injury. In: Ginsbert MD, Dietrich WD, eds. Cerebrovascular Diseases. New York: Raven Press, 1989: 373-380.

10. Chan PK, Schimdley JW, Fishman RA, Longar SM. Brain injury, edema, and vascular permeability changes induced by oxygenderived free radicals. Neurology 1984; 34: 315-320.

11. Clemens JA, Ho PP, Panetta JA. LY178002 reduces rat brain damage after transient global forebrain ischemia. Stroke 1991; 22: 1048-1052.
12. Clemens JA, Saunder RD, Ho PP, Panetta JA. The antioxidant, LY231617, reduces global ischemic neuronal injury in rats. Stroke 1993; 24: 716-723.

13. Kontos HA. Oxygen radicals in cerebral ischemia. In: Ginsberg MD, Dietrich WD, eds. Cerebrovascular Diseases. 16th Princeton Conferences. New York: Raven Press, 1989: 365-371.

14. McCord JM. Oxygen-derived free radicals in postischemic tissue injury. N Engl J Med 1985; 312: 159-163.

15. Oliver CN, Starke-Reed DE, Stadtman ER, et al. Oxidative damage to brain proteins loss of glutamine synthetase activity, and production of free radicals during ischemia/reperfusion-induced injury to gerbil brain. Proc Nat Acad Sci USA 1990; 87: 51445147.

16. Siesjö BK, Agardh CD, Bengtsson F. Free radicals and brain damage. Cereb Brain Metab 1989; 1: 165-211.

17. Siesjö BK, Lundgren J, Pahlmark K. The role of free radicals in ischemic brain damage: a hypothesis. In: Krieglstein J, Oberpichler H, eds. Pharmacology of Cerebral Ischemia. Stuttgart, Wissenschaftliche Verlagsgesellschaft, 1990: 319323.

18. Swanson RA, Morton MT, Tsao-Wu G, et al. A semiautomated method for measuring brain infarct volume. J Cereb Blood Flow Metab 1990; 10: 290-293.

19. Uemura A, Mabe $H$, Nagai $H$, Sugino $F$. Action of phospholipase $\mathrm{A}_{2}$ and $\mathrm{C}$ on free fatty acid release during complete ischemia in rat neocortex. J Neurosurg 1992; 76: 648-651.

20. Araki N, Greenberg JH, Uematsu D, Sladky JT, Reivich M. Effect of superoxide dismutase on intracellular calcium in stroke. J Cereb Blood Flow Metab 1992; 12: 43-52.

21. Cerchiari EL, Hoel TH, Safar P, Sclabassi RJ. Protective effects of combined superoxide dismutase and defroxamine on recovery of cerebral blood flow and function after cardiac arrest in dogs. Stroke 1987; 18: 869-878.

22. Liu TH, Beckman JS, Freeman BA, Hogan EL, Hsu CY. Polyethylene glycolconjugated superoxide dismutase and catalase reduce ischemic brain injury. Am J Physiol 1989; 256: H589-H593.

23. Martz D, Rayos G, Schielke GP, Betz AL. Allopurinol and dimethylthiorea reduce brain infarction following middle cerebral artery occlusion in rats. Stroke $1989 ; 20: 488-494$.

24. Martz D, Beer M, Betz AL. Dimethylthiorea reduces ischemic brain edema without affecting cerebral blood flow. J Cereb Blood Flow Metab 1990; 10: 352-357.

25. Lesiuk H, Sutherland G, Peeling J, Butler K, Saunders J. Effect of U74006F on forebrain ischemia in rats. Stroke 1991; 22: 896901.

26. Young W, Wojak JC, DeCrescito V. 21-aminosteroid reduces ion shifts and edema in the rat middle cerebral artery occlusion model of regional ischemia. Stroke 1988; 19: 1013-1019.

27. Tamura A, Graham DI, McColluch J, Teasdale GM. Focal cerebral ischemia in the rat: 1 . Description of technique and early neuropathological consequences following middle cerebral artery occlusion. J Cereb Blood Flow Metab 1981; 1: 53-60.

28. Paxinos G, and Watson C, eds. The Rat Brain in Stereotaxic Coordinates, 7th edn., New York: Academic Press, Inc., 1986.

29. Osborne KA, Shigeno T, Balarsky AM, et al. Quantitative assessment of early brain damage in a rat model of focal cerebral ischemia. J Neurol Neurosurg Psychiatry 1987; 50: 402-410.

30. Bederson JB, Pitts CH, Sabelle M, et al. Evaluation of 2, 3, 5Triphenyltetrazolium chloride as a stain for detection and quantification of experimental cerebral infarction in rats. Stroke 1986; 17: 1304-1308.

31. Park CK, Mendelow AD, Graham DI, McCulloch J, Teasdale GM Correlation of triphenyltetrazolium chloride perfusion staining with conventional neurohistology in the detection of early brain edema. Neuropathol and Appl Neurobiol 1988; 14: 289-298.

32. Lin TN, He YY, Wu G, Khan M, Hsu CY. Effect of brain edema on infarct volume in a focal cerebral ischemia model in rats. Stroke 1993; 24: 117-121.

33. Blasbert RG, Patlak CS, Fenstermacher JD. Selection of experimental conditions for the accurate determination of blood-brain transfer constants from single-time experiments: a theoretical analysis. J Cereb Blood Flow Metab 1983; 3: 215-225. 
34. Hatfield RH, Mendelow AD, Perry RH, Alvarezs LM, Modha P. Triphenyltetrazolium chloride (TTC) as a marker for ischemic changes in rat brain following permanent middle cerebral artery occlusions. Neuropathol Appl Neurobiol 1991; 17:61-67.

35. Ginsberg MD. Efficacy of calcium channel blockers in brain ischemia - a critical assessment. In: Krieglstein J, ed. Pharmacology of Cerebral Ischemia. Stuttgart, Wissenschaftliche Verlagsgesellschaft 1988: 65-73.

36. Sakurada O, Kennedy C, Jehle J, et al. Measurement of local cerebral blood flow with iodo $\left[{ }^{14} \mathrm{C}\right]$ antipyrine. Am J Physiol 1978; 234: H59-H66.

37. Schmidley JW. Free radicals in central nervous system ischemia. Stroke 1990; 21: 1086-1090.

38. Hall ED, Yonkers PA. Attenuation of postischemic cerebral hypoperfusion by the 21 -aminosteroid U74006F. Stroke 1988b; 19: 340-344.

39. Abe K, Yuki S, Kogure K. Strong attenuation of ischemic and postischemic brain edema in rats by a novel free radical scavenger. Stroke 1988; 19:480-485.

40. Xue D, Slivka A, Buchan AM. Tirilazad reduces cortical infarction after transient but not permanent focal cerebral ischemia in rats. Stroke 1992; 23: 894-899.

41. Oh SM, Betz AL. Interaction between free radicals and excitatory amino acids in the formation of ischemic brain edema in rats. Stroke 1991; 22: 915-921.
42. Hassler $O$. Deep cerebral venous system in man. A microangiographic study on its areas of drainage and its anastomoses with the superficial cerebral veins. Neurology (Minneap.) 1966; 16: 505-511.

43. Yamamoto YL, Ueda T, Shimauchi M, Diksic M. Efficacy of bypass between extracerebral artery and cerebral vein with retrograde verapamil infusion into focal cerebral ischemia in rats. Neurosurgery 1991; 29: 719-726.

44. Willmore LJ, Rubin JJ. Formation of malonaldehyde and focal brain edema induced by subpial of $\mathrm{FeCl}_{2}$ into rat isocortex. Brain Res 1982; 246: 113-119.

45. Wei HM, Chi OZ, Liu X, Sinlia AK, Weiss HR. Nitric oxide synthase inhibition after cerebral blood flow and oxygen balance in focal cerebral ischemia in rats. Stroke 1994; $25: 445-450$.

46. Ito $\mathrm{Y}$, Leblanc $R$, Yamamoto YL. Effect of retroinfusion of LY231617 in monkeys. (In preparation.)

47. Yamamoto YL, Ueda T. Effective delivery of cytoprotective agent into the ischemic tissue following the retrograde intracerebral venous infusion of vasodilator. (In Press).

48. Nagao T, Yamamoto YL, Inoue N, Ito Y. Retrograde perfusion of the cerebral vein with antioxidant LY231617 reduces brain damage in rat focal ischemia model. Neurol Med Chir 1995; 35: 85I. 